\title{
Probiotic drink from fermented mango (Mangifera indica) with addition of spinach flour (Amaranthus) high in polyphenols and food fibre
}

\author{
N. Mayulu ${ }^{1}$, Y. A. Assa ${ }^{1}$, B. J. Kepel ${ }^{2}$, F. Nurkolis ${ }^{3}$, R. Rompies ${ }^{4}$, S. Kawengian ${ }^{1}$ and \\ H. Natanael ${ }^{4}$ \\ ${ }^{1}$ Food and Nutrition Department of Sam Ratulangi University, Kampus Unsrat Bahu Street, Manado 96115, Indonesia, \\ ${ }^{2}$ Faculty of Medicine, Sam Ratulangi University, Kampus Unsrat Bahu Street, Manado, Indonesia, \\ ${ }^{3}$ Department of Biological Sciences, Faculty of Sciences and Technology, State Islamic University of Sunan Kalijaga, \\ Indonesia and \\ ${ }^{4}$ Department of Pediatrics, Sam Ratulangi University/Prof. dr. R. D. Kandou Hospital Manado, Raya Tanawangko \\ 56 street, Manado, Indonesia
}

Mango (Mangifera indica) is a tropical fruit that grows abundantly in Indonesia and has a great potential to be developed into a highvalue product rather than being eaten raw, namely as a functional drink. There are several scientific studies that show mango ${ }^{(1)}$ to be a fruit rich in dietary fibre, vitamin $\mathrm{C}$, vitamin $\mathrm{E}, \beta$-carotene, and polyphenols of the types of quercetin and kaempferol that have the potential to improve lipid profiles and lower blood glucose. In addition, spinach (Amaranthus) is a vegetable that has a nutritional content similar to mangoes and even more, such as high polyphenols. However, there is still little use of it into fermented beverage products. This study aims to process or formulate and utilize mango pulp and spinach flour to become functional food products in the form of fermented drinks. In addition, it is also to determine the levels of polyphenols (especially quercetin and kaempferol) and the total dietary fibre in these fermented products in vitro.

The formulation was carried out on 3 samples with different amounts (mango pulp: spinach flour: water) for 3 samples each S1 (900: 100: 0), S2 (850: 150: 150) and S3 (800: 200: 200). Each sample was inoculated with Lactobacillus paracasei for 60 hours and incubated in anaerobic conditions with a temperature of $30-32^{\circ} \mathrm{C}$. Analysis of polyphenols (quercetin and kaempferol) using the High Performance Liquid Chromatography (HPLC) technique at a wavelength of $415 \mathrm{~nm}$ with triplo repeat per sample. Determination of dietary fiber content using the AOAC method. The statistical test is to determine the difference between mango and water formulations on the polyphenols content of fermented products used One Way Anova.

It was found that the amount of quercetin and kaempferol in S1 was $55.89 \pm 0.01 \mu \mathrm{g} / \mathrm{g}$ and $59.98 \pm 0.02 \mu \mathrm{g} / \mathrm{g}$, respectively, for S2 were $40.66 \pm 0.02 \mu \mathrm{g} / \mathrm{g}$ and $50.42 \pm 0.04 \mu \mathrm{g} / \mathrm{g}$, and in $\mathrm{S} 351.90 \pm 0.05 \mu \mathrm{g} / \mathrm{g}$ and $48.88 \pm 0.08 \mu \mathrm{g} / \mathrm{g}$. There was a significant difference $(\mathrm{P}<0.05)$ which determined the polyphenols content between the sample formulations. The content of dietary fibre at $\mathrm{S} 1$ was $11.70 \pm 1.00 \%$, S2 was $9.80 \pm 0.06 \%$ and at S3 was $10.01 \pm 0.01 \%$. The average ash content of the three samples was $3.84 \pm 0.04 \%$ and water content was $42.01 \pm 2.01 \%$.

The highest polyphenols content was found in S1 samples with the highest levels of dietary fibre as well. Therefore, mango and spinach have great potential to be developed into fermented functional foods or probiotic drinks. The content of polyphenols (quercetin and kaempferol) in these fermented products can be a great alternative to ready-to-drink drinks, because these types of polyphenols (quercetin and kaempferol) have the ability to improve lipid profiles and stabilize blood sugar fluctuations so that they can be anti-diabetics ${ }^{(2)}$.

\section{Acknowledgements}

We thank to all of contributors for their outstanding help in formatting the abstract. The authors' responsibilities were as follows - all authors: contributed to the writing and revisions contained in the abstract; and all authors have read and approved the final abstract. Personal funding from author

\section{References}

1. Tabrizi R, Tamtaji OR, Mirhosseini N et al. (2020) Crit Rev Food Sci Nutr, 60(11), 1855-1868.

2. Ellong EN, Adenet S \& Rochefort, K (2015) Food Sci Nutr, 6(02), 242. 